\title{
O SECRETÁRIO EXECUTIVO COMO GESTOR DE MUDANÇAS ORGANIZACIONAIS NO SETOR AUTOMOBILÍSTICO
}

\section{THE EXECUTIVE SECRETARY AS A MANAGER OF ORGANIZATIONAL CHANGES IN THE AUTOMOBILE SECTOR}

\section{Karen Almeida Pereira}

Graduação em Secretariado Executivo Universidade Federal de Sergipe, UFS, Brasil E-mail: karenalmeidap@hotmail.com

\section{Jefferson David Araujo Sales}

Doutor em Administração pela Universidade Federal de Pernambuco, UFPE, Brasil.

Professor na Universidade Federal de Sergipe, UFS, Brasil

E-mail: profsales@hotmail.com 


\title{
O SECRETÁRIO EXECUTIVO COMO GESTOR DE MUDANÇAS ORGANIZACIONAIS NO SETOR AUTOMOBILÍSTICO
}

\begin{abstract}
RESUMO:
Esta pesquisa reflete sobre a atuação do profissional de secretariado como gestor de mudanças organizacionais a partir da elaboração de propostas de melhoria baseadas em processos de padronização numa assistência técnica de uma concessionária automotiva sergipana. Para se chegar aos resultados deste trabalho, foram feitas análises, interpretações e confrontações dos dados obtidos em cada etapa da investigação, a saber: observação, levantamento documental, entrevistas e questionário. No primeiro momento da investigação, e por meio da observação direta sustentada por um script observacional, os pesquisadores identificaram uma ausência de padrões que resultava numa oscilação da satisfação dos clientes e na estagnação do trabalho local. Então, no segundo momento, agora por intermédio de uma pesquisa-ação, identificou-se que a principal causa dos problemas organizacionais, ao menos no setor investigado, é a falta de padronização. Somados a isso, surge a ausência de um regular gerenciamento das pessoas e um baixo desempenho da gerência.
\end{abstract}

Palavras-chave: Processos. Padronização. Gerenciamento da rotina de trabalho. Gestão de pessoas. Prestação de serviço. Setor automobilístico.

\section{THE EXECUTIVE SECRETARY AS A MANAGER OF ORGANIZATIONAL CHANGES IN THE AUTOMOBILE SECTOR}

\begin{abstract}
:
The research reflects over the Executive Secretariat professional's performance as a manager of organizational changes from the preparation of improvement proposals based on standardizing processes in a technical support of an automotive dealership from Sergipe. In order to achieve the results in this study, analisys, interpretations and confrontations of the data obtained at every stage of the research were performed, according to the following: observation, documental survey, interviews and questionnaire. In the first stage of the investigation, and by means of direct observation sustained by an observational script, the researchers identified an absence of standards, which resulted in an oscillation in customer satisfaction and in the stagnation of the local work. So, in the second stage, now by means of an action research, lack of standardizing was identified as the main cause of organizational problems, at least in the investigated sector. Added to that, there are also the absence of a regular human resources management and a low performance management.
\end{abstract}

Keywords: Process. Standardizing. Routine work management. Human resources management. Service delivery. Automobile sector. 


\section{INTRODUÇÃO}

A missão de satisfazer clientes e, consequentemente, gerar fidelização é importante para todas as organizações. Em especial deve-se buscar a superação das expectativas de modo que haja o retorno do cliente, mesmo sabendo que esta é uma tarefa árdua para todos os envolvidos. Assim, é essencial que as organizações mantenham em longo prazo o nível de qualidade e de padrão do que é fornecido, sejam produtos ou serviços. Logo, para se obter resultados voltados para isso, é necessário que haja estabilidade e controle dos processos e o domínio operacional das atividades por meio da padronização e gerenciamento das rotinas de trabalho (Salada, 2002).

Uma vez que a empresa estabelece suas metas e objetivos, é importante ou fundamental identificar e definir quais os métodos, ou seja, determinar o caminho que norteará o alcance do seu objetivo final. Na administração esse caminho é chamado de processo. Quando uma empresa delibera e padroniza seus processos, ela define as suas atividades e o modo como elas devem ser realizadas pelos seus colaboradores, de modo a garantir e manter o ciclo padrão e qualidade do seu produto/serviço (Campos, 2004).

Considera-se relevante o campo de pesquisa dentro das Ciências Sociais Aplicadas que se volta para os processos organizacionais e sua padronização, sobretudo nas concessionárias de veículos, que em geral são de pequeno e médio porte. Logo, esta pesquisa se faz necessária não só para a melhoria da empresa objeto de estudo como também para as demais nesse âmbito e/ou para aquelas que estão em situação semelhante.

No entanto, este trabalho, de modo inovador para o campo do Secretariado Executivo, e por meio de uma pesquisa-ação, evidenciou a atuação do profissional de secretariado como gestor de mudanças organizacionais ao elaborar propostas de padronização nos processos na assistência técnica numa concessionária automotiva situada em Aracaju-SE, em prol da melhoria da prestação de serviços, uma vez que foi identificada a ausência de padrões na empresa e em seus serviços.

Os autores da pesquisa, ao notarem, de modo empírico, que a assistência técnica da empresa em que um deles trabalhava estava estagnada por não manter o nível de satisfação dos clientes estável - o que acarretou a perda da sua certificação em apenas três anos de existência -, questionaram-se sobre quais soluções seriam necessárias implantar no local para promover a qualidade da prestação de serviço e assim atingir a satisfação majoritária dos clientes.

$\mathrm{Na}$ literatura foram encontradas muitas pesquisas relacionadas ao setor automobilístico, entretanto, há de se ressaltar que são sobre fábricas e montadoras. Pouco se estuda sobre as concessionárias, que são uma extensão dessas organizações; em especial a prestação de serviços, o que acarretou em dificuldades de encontrar teses para o subsídio deste estudo.

Tendo em vista que este trabalho está dividido em cinco etapas, a seção que segue trará a literatura sobre o tema. A etapa seguinte fala sobre os procedimentos metodológicos adotados, dando ênfase à pesquisa-ação. Posteriormente são apresentadas as análises dos resultados juntamente com a proposta de padronização. O texto se encerra com as conclusões da investigação, na quinta seção. 


\section{REFERENCIAL TEÓRICO}

Esta seção busca abranger a realidade teórica do contexto da pesquisa discutindo a padronização de processos, juntamente com o gerenciamento da rotina de trabalho e das pessoas. Tais elementos fazem-se necessários para o bom desempenho da prestação de serviços das organizações, que no caso em destaque são aquelas do setor automobilístico.

\subsection{GERENCIAMENTO E PADRONIZAÇÃO DE PROCESSOS}

De modo introdutório, pode-se definir processo como um conjunto de atividades que cria ou transforma insumos em bens ou serviços, agregando valor e entregando-os aos clientes ou consumidores (Cruz, 2011). Pode-se complementar esta definição inicial com a fala de Araújo (2011, p. 25) quando diz que um processo é "uma sequência de atividades que seguem um cronograma preestabelecido, em que os recursos envolvidos e o ponto almejado se apresentam de forma simples e nítida". Na tentativa de esquematizar de forma ilustrativa as definições postas aqui do que seja um processo, surge a Figura 1 a seguir:

Figura 1. Desenho do processo

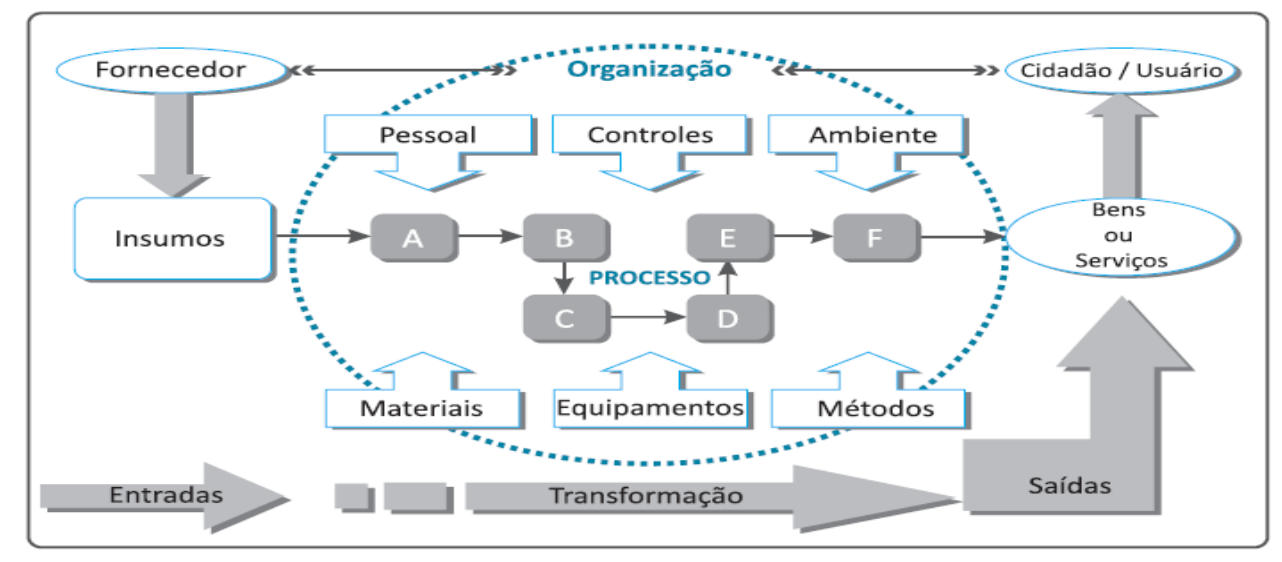

Fonte: Mendonça (2010), apud Sales (2012).

Conforme representado na figura acima, processo é "uma ordenação lógica de atividades interdependentes que apresenta um fluxo com entradas e saídas bem situadas no tempo e espaço" (Maximiano, 2009, apud Sales, 2012, p. 48). Logo, entende-se como processo o passo a passo de se realizar algo que já está definido, ou seja, é uma ordem sucessiva de atividades que tem por objetivo atingir um resultado.

Para que os resultados sejam alcançados é essencial a clareza dos elementos (insumos, recursos, atividades, informação e tempo) e objetivos (meta e clientes) que compõem um processo. De modo geral, os procedimentos constituídos pelo processo formam o seguinte ciclo: material para a produção do bem ou serviço; pessoas e equipamentos para conduzir as atividades que geram o produto; informação de como executar as tarefas e o tempo para produzi-las a fim de atender as metas traçadas e atingir o principal objetivo do processo, o cliente e a sua satisfação (Cruz, 2011).

Para realizar a projeção de um processo, primeiro a administração deve definir a missão da empresa a fim de que a equipe realize os tipos de esforços necessários para atender as expectativas 
do negócio e dos clientes. Então a missão deve ser internalizada por todos da empresa para que desempenhem trabalhos que garantam a sua sobrevivência. Segundo, o modo operacional de como realizar os processos deve ser documentado (Araújo, 2011).

Essa documentação é feita por meio da confecção de um fluxograma que explica o passo a passo, a ordem das atividades, que já foram definidas anteriormente. Posteriormente, o manual de processos é preparado. Com ele a gerência detalha e descreve as funções e atividades que serão exercidas, e este documento tem a função de ser um guia que orienta a execução delas (Araújo, 2011).

Logo, para uma empresa se estruturar de forma organizada com processos eficazes e com isso ganhar vantagem competitiva no mercado é imprescindível a definição, registro e controle de seus processos. Para tanto, isto deve ser bem definido e de forma clara para que haja o entendimento de todos na organização em busca de um resultado comum. E para isto, Las Casas (2008) afirma que é essencial a consideração de cada etapa dos processos a partir do seu início, ou seja, desde a contratação de pessoas.

Nas ciências administrativas, a padronização foi proposta por Taylor por meio da divisão do trabalho, em que o papel da gerência era o de pensar e planejar a tarefa e a do trabalhador era executá-la. Para isso, os superiores deveriam selecionar as melhores pessoas para cada tarefa, treiná-las e determinar a melhor maneira para executarem o trabalho (Caravantes; Panno e Kloeckner, 2005).

Conceituando, padrão "é o planejamento do trabalho que será executado pelo indivíduo ou organização" (Campos, 2004, p. 49). Nas empresas, as funções ocupadas pelas pessoas são categorizadas como gerenciais (gerenciamento e direção) e operacionais (supervisão e operação), sendo que a primeira define o que deve ser feito e a segunda executa; o que corresponde a $90 \%$ das atividades desempenhadas (Campos, 2004).

Ou seja, o modo de se realizar as tarefas deve ocorrer por meio do padrão, e é através dele que a administração pode delegar de forma consciente o trabalho aos operadores, tendo em vista que padrão em sua essência "é o instrumento que indica a meta (fim) e os procedimentos (meios) para a execução dos trabalhos, de tal maneira que cada um tenha condições de assumir a responsabilidade pelos resultados de seu trabalho" (Campos, 2004, p. 49).

Mas para que exista uma delegação responsável, a administração deve-se atentar em estabelecer um sistema de padronização simples no qual as informações sejam transmitidas da forma correta, de tal modo que eles possam exercer as principais atividades que lhe competem, estratégias e busca de melhorias para o negócio (Salada, 2002).

Tendo em vista que as pessoas das funções operacionais consomem mais tempo executando essas atividades, ratifica a importância de se ter um sistema de padronização eficiente. Se o modo de fazer não for eficiente, elas comprometerão a eficiência de seus trabalhos. Então, é relevante definir de forma clara o que, quem, como, quando e o porquê de se realizar as atividades, em especial as operacionais (Salada, 2002).

Uma empresa somente deve padronizar o que for necessário e importante a fim de garantir um resultado esperado, pois para implantar essa técnica demanda-se tempo, esforços e custos (Salada, 2002; Campos, 2004). Portanto, são evidenciados os principais motivos para

Revista de Gestão e Secretariado - GeSec, São Paulo, v. 6, n. 2, p 44-64, maio./agosto. 2015. 
estabelecer uma padronização, que são: garantir a qualidade de um produto/serviço; quando é necessário ter resultado estável de um processo, de modo que se houver variações comprometerá a satisfação do cliente e a qualidade do produto e; quando a falta da padronização é a causa de problemas que afetam um processo.

Todavia, para uma padronização surtir efeito, as pessoas devem ser treinadas para executar de modo único as tarefas que lhes foram conferidas. Logo, o treinamento é a essência da padronização. Os operadores somente conseguirão compreender e obedecer a um padrão se este for eficaz e se forem habilitados para isso (Salada, 2002; Campos, 2004).

\subsection{GERENCIAMENTO DA ROTINA DE TRABALHO}

Gerenciar significa estabelecer padrões, mantê-los, cumpri-los, melhorá-los, criar novos e atingir metas. Assim, o padrão é a essência do gerenciamento da rotina e esta se define como base da administração da empresa. Isto porque nele se concentram as ações de organização do ambiente e utilização do potencial das pessoas; padronização dos produtos, processos e operações; acompanhamento e verificação dos resultados desses processos em comparação com as metas; ação corretiva quando há disfunções nesses processos e nos resultados, comparados com a meta e busca de melhoria constante (Campos, 2004).

Com base na definição clara das funções e responsabilidade de cada pessoa, no cumprimento dos padrões e na verificação dos procedimentos, Campos (2004) determina a execução das atividades de cada função quando os processos estão normais e quando há disfunções como pode ser visto na Figura 2:

Figura 2: Atividades das funções operações normais e com disfunções.

\begin{tabular}{|c|c|c|c|}
\hline \multicolumn{2}{|c|}{ FUNÇÕES SITUAÇÃO } & NORMAL & OCORRÊNCIA DE DISFUNÇÕES \\
\hline \multirow{2}{*}{ 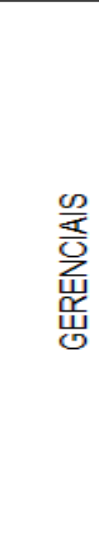 } & DIREÇÃO & $\begin{array}{l}\text { Estabelece METAS } \\
\text { que garantem a } \\
\text { sobrevivência da } \\
\text { empresa a partir do } \\
\text { plano estratégico. }\end{array}$ & $\begin{array}{l}\text { Estabelece METAS para corrigir a } \\
\text { situação atual } \\
\text { Compreende relatórios das } \\
\text { disfunções. }\end{array}$ \\
\hline & GERÊNCIA & $\begin{array}{l}\text { Treina função } \\
\text { supervisão. } \\
\text { Atinge metas (PDCA). }\end{array}$ & $\begin{array}{l}\text { Elabora relatórios das disfunções. } \\
\text { Elimina as disfunções crônicas, } \\
\text { atuando nas causas fundamentais } \\
\text { (PDCA). } \\
\text { Verifica frequentemente as } \\
\text { disfunções atuando } \\
\text { complementarmente à supervisão. }\end{array}$ \\
\hline \multirow{2}{*}{ 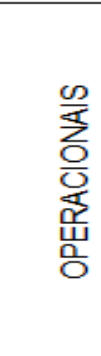 } & SUPERVISÃO & $\begin{array}{l}\text { Treina a função } \\
\text { operação. } \\
\text { Verifica se a função } \\
\text { operacional está } \\
\text { cumprindo os } \\
\text { procedimentos padrão. }\end{array}$ & $\begin{array}{l}\text { Registra as anomalias e relata } \\
\text { para a função gerencial. } \\
\text { Conduz análise das disfunções, } \\
\text { atacando causas imediatas (p. ex: } \\
\text { o padrão foi cumprido?) }\end{array}$ \\
\hline & OPERAÇÃO & $\begin{array}{l}\text { Cumpre os } \\
\text { procedimentos padrão. }\end{array}$ & Relata as disfunçôes. \\
\hline
\end{tabular}

Fonte: Adaptado de Campos (2004). 
Então, por meio da definição correta da função de cada pessoa e com a identificação e correção das disfunções (reclamação de clientes, quebra de equipamento, atrasos nas entregas) a empresa garante um bom desempenho nas suas atividades. É importante que os trabalhos estejam em conformidade e as pessoas executem conforme os padrões, pois quando isso não acontece a empresa perde tempo e competitividade, uma vez que para diagnosticar e consertar as falhas é gerado um retrabalho que não agrega valor a ela, empresa (Campos, 2004; Cruz, 2011).

Ou seja, com o desempenho correto de cada função, seja em situações normais ou não, uma empresa tem domínio de suas operações, de seus resultados, das disfunções e da execução do trabalho das pessoas de modo que sejam tomadas intervenções para garantir a qualidade do produto/serviço, a satisfação do cliente e a sustentabilidade da empresa.

Como uma forma de controlar a qualidade a fim de atingir as metas e ganhar vantagem competitiva, ela deve utilizar a técnica de gestão usada para gerenciar a rotina, o ciclo PDCA (do inglês Plan, Do, Check, Action), cuja essência está em obter melhorias (Campos, 2004), conforme Figura 3:

Figura 3. Ciclo PDCA

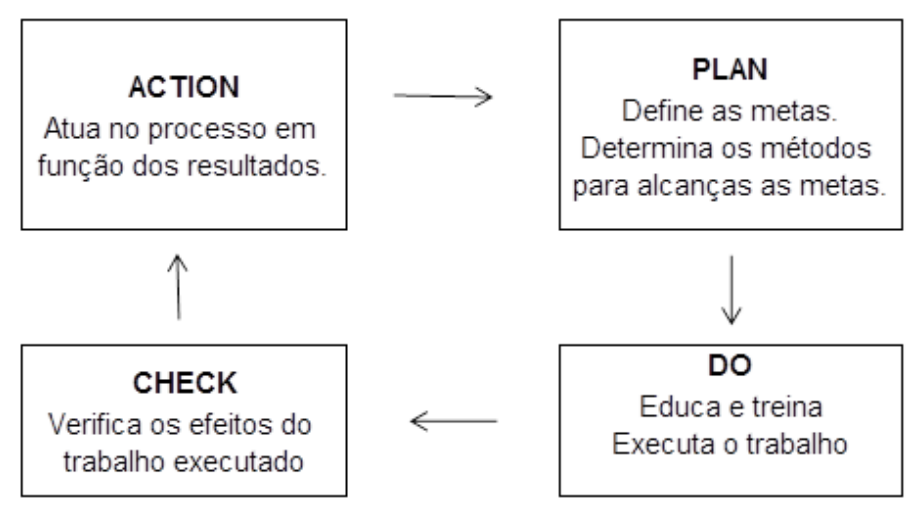

Fonte: Adaptado de Campos (2004).

Tais ações devem ser realizadas pela gerência da seguinte forma: para cada meta deve ser criado um plano de ação que se baseia no método PDCA de modo que as atividades sejam realizadas de acordo com a técnica. O gestor precisa garantir que nada seja feito a não ser que esteja no plano de ação (Campos, 2004).

Contudo, para que haja um gerenciamento de rotina é imprescindível a presença de padrões. E acoplados a estes, a administração precisa definir e realizar na íntegra todas as suas metas e ações. Assim, um gerenciamento eficaz na busca de melhoria consiste nas seguintes características: padronização, definição dos fluxogramas, avaliação dos processos e treinamento no trabalho; eliminação e relato das disfunções, ação corretiva e melhoria no processo; organização do gerenciamento, descrição do negócio, definição de metas, treinamento no PDCA; identificação dos problemas, criação dos planos de ação (PDCA) (Campos, 2004).

Assim, por meio do gerenciamento da rotina de trabalho, ou seja, na execução e verificação da execução dos padrões, a empresa ganha produtividade e a garantia da qualidade do produto/serviço. 


\subsection{GERENCIAMENTO DE PESSOAS NA PRESTAÇÃO DE SERVIÇO}

De acordo com Gronroos (2003), uma empresa deve desempenhar ações que atendam as necessidades dos clientes e gere satisfação para eles. Logo, as pessoas têm papel fundamental na prestação de serviços uma vez que é por meio delas que as necessidades dos clientes são atendidas.

Como o cliente interage apenas com uma parte do processo - o pessoal do atendimento -, é por meio desse processo que ele tem a percepção da qualidade e do desempenho da empresa. Assim, os subprocessos devem ser executados e as pessoas devem interagir e atender umas às outras de tal modo que o cliente deve perceber o serviço apenas com um único processo (Gronroos, 2003).

Acrescentando a este pensamento, Lovelock, Wirtz e Hemzo (2011) afirmam que os funcionários da linha de frente são determinantes para a excelência do serviço e vantagem competitiva às organizações desse âmbito, uma vez que sob a ótica do cliente eles são a empresa e é por meio deles que são entregues os serviços. Então, espera-se que os funcionários sejam corteses, eficientes e ágeis em realizar as atividades operacionais e produtivas.

Sendo assim, a empresa que almeja satisfazer o cliente e ser um diferencial no mercado deve investir na capacitação das pessoas para obter sucesso. Quando não há esse investimento nos funcionários, a fim de que eles realizem um trabalho produtivo e um atendimento de qualidade, os superiores geram, segundo Lovelock et al. (2011), o ciclo de fracasso. Este fracasso atinge o funcionário e o cliente.

O início do fracasso do funcionário é determinado por cargos restritos, pouca capacitação, prioridade em regras em vez dos serviços, e salários baixos. Então esses fatores geram a insatisfação e a incapacidade em resolver os problemas dos clientes e prestar um bom atendimento. Por sua vez, o cliente fica insatisfeito com o atendimento ou serviço recebido e isto acarreta resultados baixos à empresa e a rotatividade dos funcionários (Lovelock et al., 2011).

Ainda segundo Lovelock et al. (2011), o fator para a que este ciclo exista e perpetue numa empresa é um problema gerencial, que se deve à falta de seleção adequada e de capacitação dos seus funcionários. Para o autor, os gerentes não podem continuar justificando a existência desses fracassos com a desculpa de que não há bons profissionais no mercado ou que eles custam caro.

Segundo Hoffman e Bateson (2009, p. 306), "contratar, treinar e recompensar pessoal eficaz contribui muito para a qualidade interna do serviço". Logo, por meio de treinamento, capacitação e recrutamento adequado o funcionário executa o trabalho da melhor forma para que prolongue o tempo de vida dele na organização e assim fideliza seus clientes com prestação de serviços com qualidade e com um excelente atendimento.

Portanto, quando a empresa adota essas medidas ela gera o ciclo do sucesso, que de acordo com Lovelock et al. (2011) mantém o funcionário satisfeito. Isso gera bons resultados e conquista a fidelidade dos clientes e, consequentemente, a empresa ganha mais lucro mantendo-os em vez de investir na busca de novos. Segundo os autores, o ciclo é composto da seguinte forma: o funcionário tem descrição de cargos mais amplos, treinamento intensivo, bom salário, o que gera sua satisfação, comprometimento, alta qualidade no serviço, redução da rotatividade e margem de lucro alta. Posteriormente, o cliente que se beneficia com um atendimento e serviços de qualidade, sente alta satisfação, repete a experiência e se fideliza com a empresa. 


\subsection{PRESTAÇÃO DE SERVIÇOS NO SETOR AUTOMOBILÍSTICO}

Diante da gama de marcas disponíveis no mercado, uma forma das empresas ganharem vantagem competitiva sobre as outras no tocante a conquistar seus clientes, é satisfazê-los oferecendo serviços de apoio aos produtos (Rapp e Collins, 1996 apud Urdan e Zuñiga, 2001). Assim, as montadoras com o objetivo central de vender seus veículos tinham a prestação de serviço como um suporte, um atrativo para facilitar a compra desses bens por meio de financiamentos, seguros, garantia estendida, comercialização de peças originais, manutenções e reparações (Muniz, 2005).

Com o crescimento das tecnologias na fabricação dos veículos, o que os tem tornado mais complexos, esses bens têm estado cada vez mais similares aos olhos dos consumidores. Logo, a prestação de serviço nesse âmbito se tornou um diferencial na escolha da compra de um automóvel, sobretudo a assistência técnica. Se os veículos estão cada vez mais parecidos, a opção de obter tal bem estará vinculada aos benefícios com a prestação de serviço na assistência técnica (Urdan \& Zuñiga, 2001).

A prestação de serviços no ramo automobilístico é oferecida pelas montadoras por meio das concessionárias e dos seus departamentos de vendas e pós-vendas, onde estão centradas a comercialização de bens e a assistência técnica. "Assim, as atividades das concessionárias, atuando de acordo com as necessidades dos clientes, teriam um papel bem mais importante no processo de compra de um veículo" (Urdan \& Zuñiga, 2001, p. 34). Isso porque, a fidelidade ao produto está na satisfação com o serviço da assistência técnica sendo que o seu aprimoramento é considerado de suma importância de modo a satisfazer os clientes.

Urdan e Zuñiga (2001) dizem que embora as montadoras tenham um processo gerencial de primeiro mundo, as concessionárias brasileiras são de pequeno ou médio porte e não possuem uma assimilação das competências gerenciais, logo, têm dificuldades de implantar ações que melhorem os serviços e satisfaçam os clientes.

Nos últimos anos, as assistências técnicas das concessionárias estão cada vez mais sendo um ponto estratégico e essencial para fidelizar clientes e garantir a permanência destas empresas no mercado. Tendo em vista a redução da venda de veículos leves após impactos causados com a crise financeira de 2008 e 2009, especialistas afirmam que a tendência é que essa diminuição seja irreversível (Dealer, 2013).

Logo, uma excelente prestação de serviços almejará a satisfação e fidelidade do cliente e este repetirá o uso deste bem, garantindo assim a sustentabilidade destas empresas.

\section{METODOLOGIA}

Esta pesquisa classifica-se como sendo descritiva com abordagem qualitativa. De natureza aplicada, esta é uma pesquisa-ação por consistir num "planejamento de uma ação destinada a enfrentar o problema que foi o objeto da investigação" (Gil, 2007, p. 146). Os pesquisadores identificaram o inconveniente no ambiente estudado, a concessionária, e posteriormente elaboraram um conjunto de ações que desembocaram em propostas de padronização para a resolução dos 
problemas encontrados e para eventual a melhoria do local em estudo.

Segundo Thiollent (2005, p. 18), a ideia de pesquisa-ação não é como as convencionais que se limitam em relatórios ou em levantamento de dados para serem guardados. Com este tipo de pesquisa os pesquisadores "pretendem desempenhar um papel ativo na própria realidade dos fatos observados". Isto por que a pesquisa não constitui nas pessoas e sim pela situação e dos problemas encontrados. Logo, o intuito da pesquisa-ação é solucionar ou pelo menos esclarecer os problemas da situação observada.

É importante destacar que embora a metodologia da pesquisa-ação seja similar à pesquisa participante, pois possui caráter participativo, elas não devem ser confundidas. Na primeira existe a "ação planejada sobre os problemas detectados" e na segunda "nem sempre há uma ação planejada [...] e o resultado da pesquisa fica na consciência dos participantes" (Thiollent, 2009, p. 9).

Na pesquisa-ação, as principais coletas de dados usadas são por meio de entrevista, tanto em conjunto como individuais e observação participante. Com relação às informações que já existem no local, várias técnicas podem ser usadas para analisar os conteúdos (Thiollent, 2005).

A pesquisa teve quatro técnicas como instrumentos de coleta de dados: a) levantamento documental; b) entrevistas; c) observação participativa; e d) questionário.

a) Levantamento documental: foram levantados os resultados das pesquisas de satisfação do cliente do período de 2011 a 2013 que são realizadas pelo fabricante. Os dados foram coletados e analisados numa planilha eletrônica a fim de comparar os resultados entre os anos. Preferiu-se não realizar novas pesquisas com os clientes tendo em vista que estas pesquisas de satisfação já são realizadas mensalmente.

b) Entrevistas: Os sujeitos da pesquisa foram os funcionários do departamento investigado (exceto a assistente, porque é a pesquisadora) e o gerente que totalizam o número de 26 pessoas. Eles têm idade entre 19 a 56 anos. Foram realizadas entrevistas semiestruturadas com os funcionários a fim de identificar o funcionamento dos processos na assistência técnica levando em consideração todas as etapas dos processos, da contratação até o objetivo final e se há utilização do ciclo PDCA. Posteriormente, foi feita uma contagem nas respostas tendo em vista os números divergentes de algumas delas e realizada a análise dos resultados.

c) Observação participativa: Por esse método foi possível observar como de fato os processos funcionam e como as pessoas os entendem e os fazem. Quatro vezes por semana, durante dois meses um dos pesquisadores permaneceu na recepção da assistência técnica nos dois momentos de atendimento, dois dias pela manhã quando os clientes deixam o veículo para fazer as manutenções e dois dias no horário da tarde quando eles os retiram da concessionária. Cada observação teve a duração de trinta minutos e foram feitas de modo aleatório com o auxilio de um script.

d) Questionário: Com o gerente, foi aplicado um questionário com perguntas abertas no mesmo formato das entrevistas feita com os funcionários, o qual teve o intuito de investigar o funcionamento dos processos e o porquê de as ações gerenciais não serem voltadas para a qualidade nos serviços.

Julgou-se que a estratégia da pesquisa-ação se encaixava nesse tipo de contexto pelo conjunto de características peculiares surgidos no cenário investigado. A ideia de também propor 
melhorias impulsionou ainda mais a implementação da pesquisa. A seguir, são apresentados modularmente os resultados do estudo.

\section{ANÁLISE DOS RESULTADOS}

Esta seção divide-se em cinco momentos que retratam as etapas da pesquisa-ação. Assim, parte-se dos resultados do levantamento documental, que foi o marco de partida da investigação. A segunda etapa é resultante da observação feita no ambiente de trabalho investigado. Na sequência, surgem os resultados oriundos das entrevistas que são complementadas com a quarta etapa em que se apresentam os resultados da aplicação do questionário. E, por fim, é ilustrada a proposta de padronização para a organização estudada.

\subsection{RESULTADOS DO LEVANTAMENTO DOCUMENTAL}

As análises do levantamento documental foram baseadas nos resultados da pesquisa de satisfação realizada mensalmente pelo fabricante da marca. O método usado para a coleta de informações da satisfação é através de ligação telefônica em que são realizados contatos com os clientes que estiveram na concessionária para a realização de algum serviço, exclusivamente no departamento de pós-venda, no período entre sete a sessenta dias após o evento.

O questionário adotado pela montadora é baseado na percepção da qualidade dos serviços e abrange os processos de atendimento: recepção, atendente, técnico, serviços executados e custos, sendo que para este trabalho não serão analisadas as questões de custos, pois não são relevantes à pesquisa.

A variação de notas mensais da concessionária são significativas tendo o mínimo de 33,3\% e máxima de $87,5 \%$ - aplicada uma única vez. Porém, a média de nota mensal está abaixo de $70 \%$ de satisfação, e a meta da satisfação estipulada pela montadora é de, no mínimo, 85\% mensal. Para ficar mais clara a evidência desses fatos, a Figura 4 abaixo mostra a oscilação dessas notas nos três anos de empresa:

Figura 4. Demonstração da oscilação das notas mensais

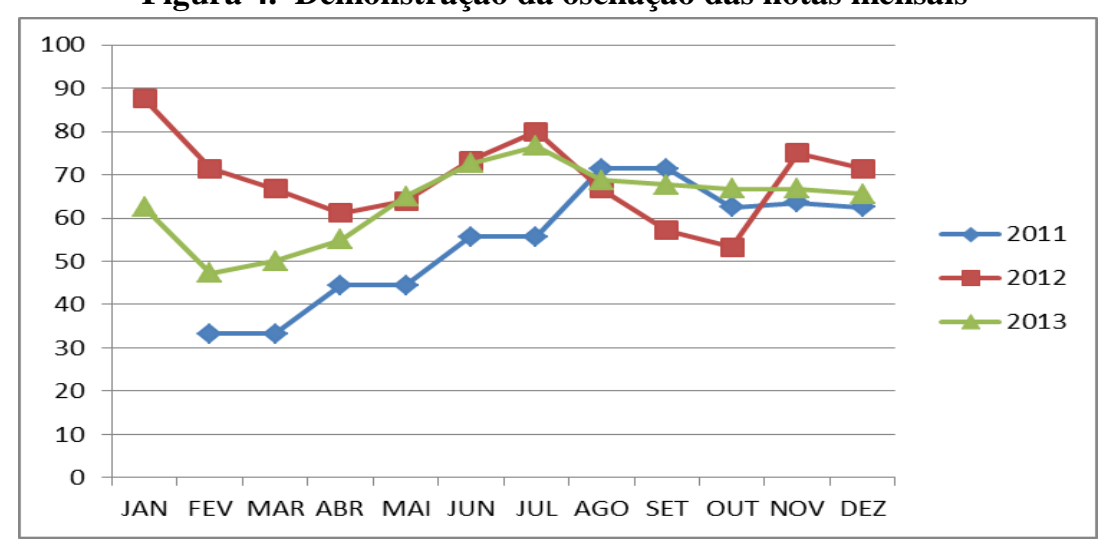

Fonte: Dados do levantamento documental. 
Observa-se a discrepância da satisfação dos clientes mensais e anuais e falta planejamento para mudar esse cenário, pois uma vez que a oscilação é contínua, verifica-se que não há estratégias de mudança e de melhoria.

Entretanto, após a observação empírica do profissional de secretariado em verificar que existia oscilação nas notas e que os motivos de insatisfação eram sempre os mesmos, ele abordou esses assuntos com o gestor em reuniões e propôs que deveria haver planos de ação para corrigir as falhas.

Mas isso não é e não foi o suficiente uma vez que a melhoria é apenas em curto prazo e só mostrar o erro e não dar a solução de nada resolve. Há muitos outros problemas que a gerência precisa solucionar.

No que diz respeito aos motivos de insatisfação dos clientes com os serviços do departamento, estes justificam a atribuição de notas iguais e abaixo de sete, conforme Tabela 1:

Tabela 1. Motivos de insatisfação

\begin{tabular}{|l|l|l|l|}
\hline MOTIVO & $\mathbf{2 0 1 1}$ & $\mathbf{2 0 1 2}$ & $\mathbf{2 0 1 3}$ \\
\hline Não resolvem os problemas & $33,3 \%$ & $20 \%$ & $15 \%$ \\
\hline Serviços não realizados & $20 \%$ & $15 \%$ & $12 \%$ \\
\hline Falta de retorno/contato & $20 \%$ & $7,5 \%$ & $4,5 \%$ \\
\hline Falta de peças & $13,3 \%$ & $12,5 \%$ & $15,8 \%$ \\
\hline Falta de qualidade/serviço mal executado & $13,3 \%$ & $10 \%$ & $16,5 \%$ \\
\hline Veículo sujo/mal lavado & $13,3 \%$ & $7,5 \%$ & $4,5 \%$ \\
\hline Alto preço mão de obra & $6,6 \%$ & $7,5 \%$ & $8 \%$ \\
\hline Mau atendimento/falta de cortesia & - & $15 \%$ & $24 \%$ \\
\hline Demora na entrega do veículo & $13,3 \%$ & - & $7,5 \%$ \\
\hline Falta de informação sobre o serviço executado & - & $10 \%$ & $8 \%$ \\
\hline Problemas com garantia & $6,6 \%$ & - & $7,5 \%$ \\
\hline Demora no atendimento & - & $7,5 \%$ & $5 \%$ \\
\hline Funcionários sem capacitação técnica & - & $30 \%$ & - \\
\hline Má instalação da concessionária & - & $7,5 \%$ & - \\
\hline Quant. de nota acumulada & $\mathbf{1 5}$ & $\mathbf{4 0}$ & $\mathbf{1 3 3}$ \\
\hline
\end{tabular}

Fonte: Dados do levantamento documental.

Os seis principais motivos de insatisfação estão presentes nos três anos consecutivos, o que corrobora mais uma vez a falta de planejamento e de ações estratégicas para melhorar o serviço no departamento.

Esses problemas estão relacionados especialmente com a falta de capacitação das pessoas 
em executar os serviços, como será visto de maneira mais detalhada no item 4.3 deste capítulo. E por essa ausência há o retrabalho, pois se o serviço não é bem executado o veículo volta à concessionária e assim sucessivamente. Logo, ao invés de gastar esforços em treinamentos ou na prestação de um bom serviço, perde-se tempo em reparar erros. E por trás disso tudo está a falta de gerenciamento e de planos estratégicos para a melhoria na prestação de serviços, conforme advogam autores como Urdan e Zuñiga (2001) e Muniz (2005).

\subsection{RESULTADOS DA OBSERVAÇÃO}

\subsubsection{FUNCIONAMENTO DO MACROPROCESSO NO PÓS-VENDA}

É no departamento de pós-venda que os serviços nos veículos são realizados, são eles: manutenção, reparação, garantia e venda de peças e acessórios. Ele é composto pelos seguintes setores: agendamento (um agente de agendamento), recepção (dois atendentes), administrativo (um assistente de gerente), assistência técnica (seis mecânicos), qualidade técnica (dois encarregados de qualidade), garantia (um analista), peças e acessórios (um vendedor de peças e outro de acessórios, um estoquista, um estagiário e um instalador de acessórios); funilaria e pintura (um encarregado, um funileiro, um pintor, um montador, dois preparadores, um auxiliar de montagem e um polidor) e posto de lavagem que é terceirizado (um consultor e três lavadores).

Cada setor é responsável por diferentes ações que correspondem a cada etapa do macroprocesso no departamento.

Verificou-se que não há problema com o fluxograma do funcionamento do macroprocesso, nem com cada etapa (criado pela montadora). O que foi observado é que as pessoas têm dificuldades em executar os subprocessos dessas etapas, de desempenhá-los corretamente e/ou não fazem.

Identificou-se que a demora do funcionamento do macroprocesso é justificada pela falta de domínio de conhecimento dos subprocessos, em especial pelos atendentes.

O que pôde ser observado é que o número de reclamações e insatisfações registradas diariamente seja com o atendimento, com a qualidade de serviço, com a falta de retorno etc. é muito maior que o número de reclamações realizadas pela pesquisa de satisfação. Quando os atendentes ligam no dia seguinte para os clientes para saber informações a respeito do serviço executado, a quantidade de insatisfação com o serviço e com o retorno do problema é superior e preocupante.

De modo geral, por meio do funcionamento do macroprocesso, observou-se que este é programado pela montadora e há um ciclo coerente. Entretanto falta entendimento das pessoas sobre o seu funcionamento, pois é como se elas não soubessem com clareza e certeza aquilo que estão fazendo. Dessa forma, isso acarreta serviços demorados, sem qualidade e, sobretudo sem preocupação com o cliente. Ao se fazer um paralelo com o que menciona Lovelock et al. (2011), é possível que isto se justifique devido à falta de treinamentos dos funcionários, conforme será evidenciado no item a seguir. 


\subsection{ANÁLISE DOS RESULTADOS DAS ENTREVISTAS}

Considerando o tempo de função na empresa a fim de verificar a rotatividade das pessoas, $56 \%$ estão trabalhando a menos de um ano e $44 \%$ de um a três anos. Logo, nota-se que há uma rotatividade considerada, tendo em vista que mais da metade não completou um ano na empresa, sendo que a mesma tem apenas três anos.

Já em relação ao tempo de experiência na profissão que está sendo exercida na empresa, $60 \%$ nunca desempenharam a atividade antes e $40 \%$ já trabalhavam na área.

Questionados sobre como foi o ingresso na empresa, este se deu de formas diversas conforme Tabela 2 a seguir:

Tabela 2. Forma de ingresso na empresa

\begin{tabular}{ll}
\hline Tipo de ingresso & Quantidade de funcionários \\
\hline Indicação + entrevista & 11 \\
Seleção & 2 \\
Transferência de empresa do Grupo & 2 \\
Estágio & 2 \\
Currículo & 3 \\
Transferência da antiga empresa & \\
que representava a marca & 4 \\
Sem entrevista & 1 \\
TOTAL & $\mathbf{2 5}$ \\
\hline
\end{tabular}

Fonte: Dados da pesquisa.

É notória a falta de padrões para a seleção de pessoas para trabalhar no departamento. O modo de contratação é tão vago e heterogêneo que, durante o período de observação, um funcionário que havia sido demitido fez o exame admissional junto com o demissional, pois não havia realizado quando ingressou na empresa. Neste sentido, Urdan e Zuñiga (2001) corroboram os dados listados aqui uma vez que, segundo eles, esta é uma realidade inerente ao setor.

Já em relação ao conhecimento dos funcionários acerca da missão, visão e valores da empresa, $40 \%$ confirmaram ter conhecimento, mas não sabem descrever quais são; $32 \%$ afirmaram que não sabem; $16 \%$ revelam que sabem e $12 \%$ alegam saber mais ou menos, conforme Figura 5 abaixo:

Figura 5. Conhecimento sobre missão, visão e valores da empresa

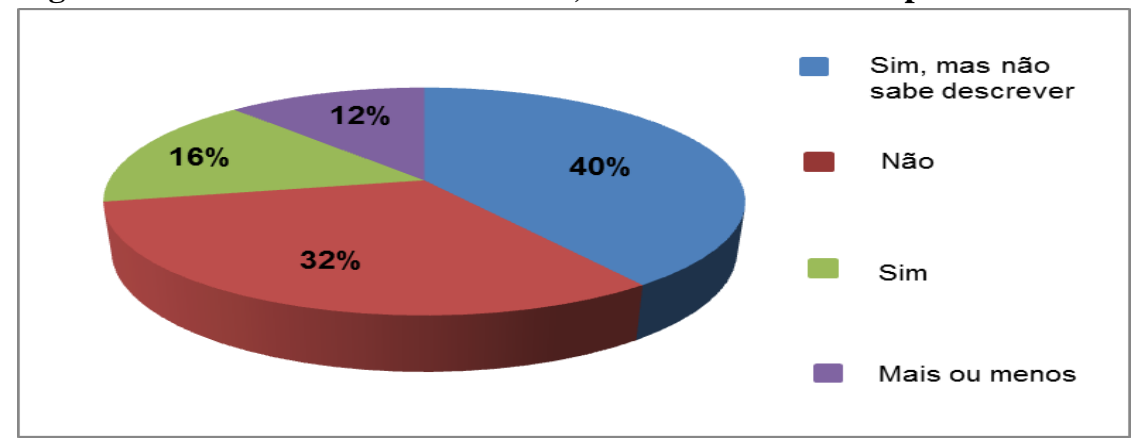

Fonte: Dados da pesquisa. 
Sobre quais são a missão, visão e valores, dos respondentes que afirmaram que sabem e/ou que sabem pouco, eles apenas citaram acerca da missão, que para eles englobam os três passos. Assim, responderam que a missão da empresa é ter consciência, executar bem as suas funções, trabalhar unido, executar os serviços, prestar um bom serviço, preocupar-se com o meio ambiente, ter certificação máxima e ser reconhecida como a melhor empresa do país.

Segundo eles, esse conhecimento é por "minha percepção" e por que "o gerente fala nas reuniões". Observa-se então que ou a missão não está bem definida ou não é passada claramente para os funcionários uma vez que são respostas divergentes e sem coerência.

Quando perguntados se após a contratação os funcionários receberam documentação sobre os processos do departamento, seu funcionamento e de seus cargos, fluxograma etc. sete alegaram terem recebido e 18 afirmaram que não, só souberam verbalmente.

Dos sete funcionários que receberam algum tipo de documentação, cinco receberam a definição de cargo que descreve as responsabilidades, e dois funcionários só receberam com um tempo depois de atuação na empresa.

Os outros dois que receberam registros foram o analista de garantia que afirmou ter recebido um manual de garantia que é fornecido pela fábrica e o auxiliar de estoque que recebeu uma planilha, também fornecida pela montadora, a qual discorre sobre a gestão de estoque e o seu funcionamento, além da apostila de treinamento do gestor quando este fez o curso de gestão de estoque.

Tendo em vista que a empresa não tem registro do funcionamento dos processos e seus subprocessos, a maioria respondeu que aprendeu os processos e o seu trabalho sob orientação dos colegas e/ou superior.

Sobre o processo de treinamento, $92 \%$ dos entrevistados afirmaram que não tiveram treinamento quando exerceram suas funções e $8 \%$ confirmaram que tiveram, sendo que um vendedor de acessórios teve treinamento pelo site.

Cabe destacar que apenas três mecânicos tinham experiência de profissão, ou seja, os demais além de não terem experiência não tiveram treinamento. Logo, aprenderam na prática a consertar veículos.

No que diz respeito à rotina de trabalho estabelecida, os funcionários da assistência técnica e da funilaria, ou seja, os técnicos relataram que não há como estabelecer uma rotina uma vez que eles desempenham os trabalhos de acordo com as necessidades de cada veículo. Logo, eles executam as atividades conforme vão surgindo.

Já os demais funcionários afirmaram que não há uma rotina de trabalho preestabelecida pela empresa, há apenas uma orientação de como deve ser e eles executam conforme acham conveniente. 


\subsection{ANÁLISE DO QUESTIONÁRIO APLICADO AO GESTOR}

O gerente do departamento de pós-vendas tem 40 anos, está atuando na empresa desde o início, possui 10 anos de experiência e tem o ensino superior incompleto.

De acordo com o gerente, existem padrões definidos e registrados em todos os processos da empresa desde a contratação até a demissão - o que contradiz totalmente o que foi notado nas entrevistas dos funcionários.

Sobre a missão, visão, valores, quais são os objetivos da empresa; o gestor declarou que esses pontos estão sendo aprimorados para que sejam implantados com os colaboradores atuais por meio de dinâmicas coletivas e no que se refere a possíveis novos contratados, a serem passados no momento da contratação.

Logo, a resposta não foi concreta e nem houve a confirmação de quais eram os objetivos da empresa/departamento. A fala do gestor é futura. Assim, justifica-se o porquê de os funcionários não terem entendimento nem conhecimento correto desses pontos, pois não são bem definidos e claros. Ressalta-se que esta fala futura foi reforçada em todas as respostas do questionário.

Segundo afirmação do gestor, após ser questionado sobre a capacitação dos funcionários, uma vez que a maioria não tem supervisão de um superior, eles são capacitados o suficiente para que as atividades possam lhe ser delegadas, pois para o gerente o bastante é que eles queiram fazer.

Já no que diz respeito ao porquê de o departamento não conseguir atingir meta e a satisfação majoritária dos clientes, o gerente garante que o mais comum é a falta de comprometimento dos funcionários, dificuldade de relacionamento com o cliente e falhas na comunicação.

O gestor afirma que a qualidade na prestação de serviços é o principal foco do departamento, mas a dificuldade para prestar um bom serviço é o problema de encontrar mão de obra, fato que tem contribuído para o baixo desempenho.

Logo, nota-se que a desculpa para não ter qualidade no serviço é a falta de mão de obra no mercado.

$\mathrm{Na}$ questão sobre se o gestor tem dificuldades em gerenciar as pessoas, em criar planos de ações ou planejamento, ele afirma que não há dificuldade em nenhum desses pontos. Na realidade, o que existe é a falta de comprometimento dos envolvidos e, novamente, falta de mão de obra no mercado para reposição.

Já com relação por que não há padrões nos processos do departamento, na opinião do gerente todos os processos têm padrões e são extremamente importantes e ele os valoriza. Mas é preciso que cada profissional aprecie sua oportunidade colocando-os em prática.

Mas como pode ser observado durante as respostas deste trabalho não há padrão nenhum relacionado aos processos, desde a contratação até o último processo de atendimento.

No final do questionário o gestor acrescentou que estão em um momento de reestruturação, que está acreditando nos novos talentos sendo que estes têm somado e acreditado no que fazem, tornando-se exemplos para os demais.

Mas diante de suas respostas, a reestruturação não está ligada à melhoria dos serviços e dos 
processos para que assim mude o cenário atual. Suas palavras e argumentos caminham no sentido de justificar as causas dos problemas e suas soluções nas pessoas e no talento delas - ele espera o resultado das pessoas sem dar a formação requerida e, sobretudo, treinamento para isto.

\subsection{PROPOSTA DE PADRONIZAÇÃO}

Diante do que foi observado e analisado, o primeiro passo a ser dado é a recriação e registro de modo claro, objetivo e dentro da realidade da missão, visão, valores da empresa e os objetivos de cada departamento. Se os funcionários que trabalham no pós-venda não têm conhecimento, a mesma situação provavelmente poderá ser observada com outros funcionários. E para que uma empresa dê certo, todos na organização precisam estar envolvidos, uma vez que cada setor complementa os processos. Isso deve ser realizado pela diretoria juntamente com seus gestores, com o auxílio do profissional de secretariado.

Posteriormente, deve-se fazer uma análise do funcionamento de todos os processos, alterar os que estão equivocados ou com excesso de burocracia. Após isto, faz o registro deles e transfere na intranet os que são mais utilizados pelos funcionários, para o acesso prático no dia a dia. Em seguida, a segunda parte é a criação de treinamento no trabalho. Cada cargo deve ter seu treinamento específico, os supervisores precisam de treinamento e possuir mais conhecimento do que os seus subordinados, sobretudo desenvolver habilidades de liderança. Logo, eles podem ser treinados pelo próprio gerente tendo em vista que ele realizou alguns cursos, ressaltando que esses treinamentos devem ser baseados conforme a necessidade de cada funcionário. E com o treinamento realizado no próprio trabalho, diminuem-se os custos com treinamentos externos. Estes devem ser feitos para aperfeiçoamento e não para aprendizado.

\section{Figura 6. Proposta de melhoria}

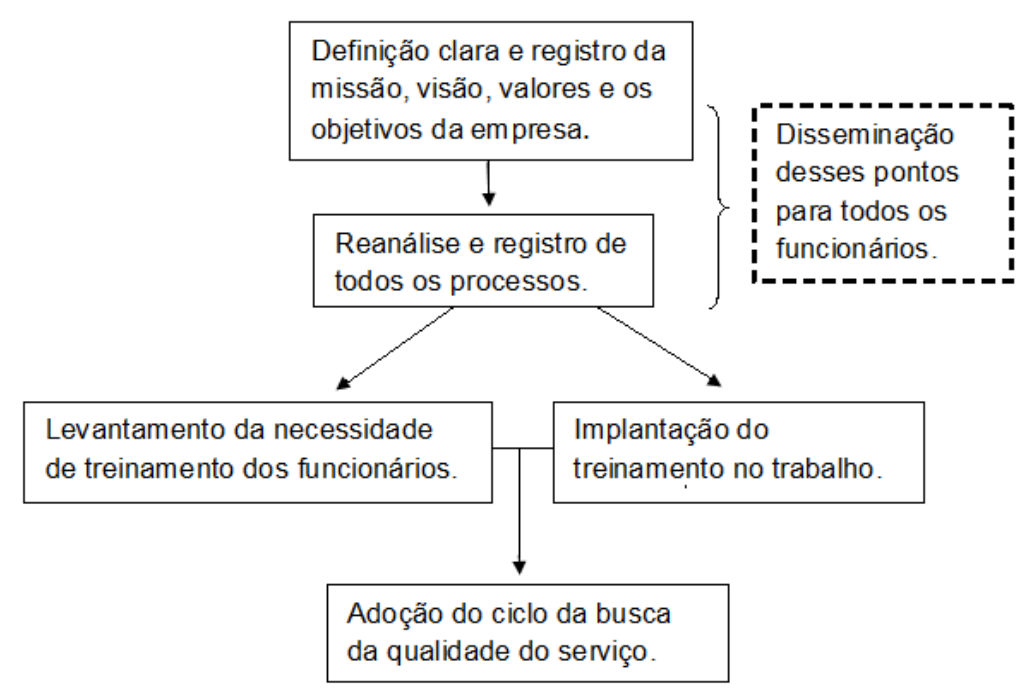

Fonte: Autores da pesquisa.

A última etapa a ser desenvolvida e aplicada é o ciclo da busca da qualidade do serviço baseado no PDCA (planejar, executar e controlar) e nas disfunções do departamento. Após a diretoria definir as metas juntamente com o gestor, este cria metas com os supervisores para atingir

o objetivo geral. Após terem as metas definidas e registradas, medidas deverão ser

Revista de Gestão e Secretariado - GeSec, São Paulo, v. 6, n. 2, p 44-64, maio./agosto. 2015. 
desenvolvidas para o acompanhamento e verificação de pontos/problemas específicos no departamento. Posteriormente, treina-se o pessoal para que execute o que foi proposto, os supervisores acompanham periodicamente cada desenvolvimento e qualidade do que está sendo feito, faz a verificação e adota a correção. E assim reinicia o ciclo, conforme Figura 7.

Figura 7. Ciclo da busca da qualidade no serviço

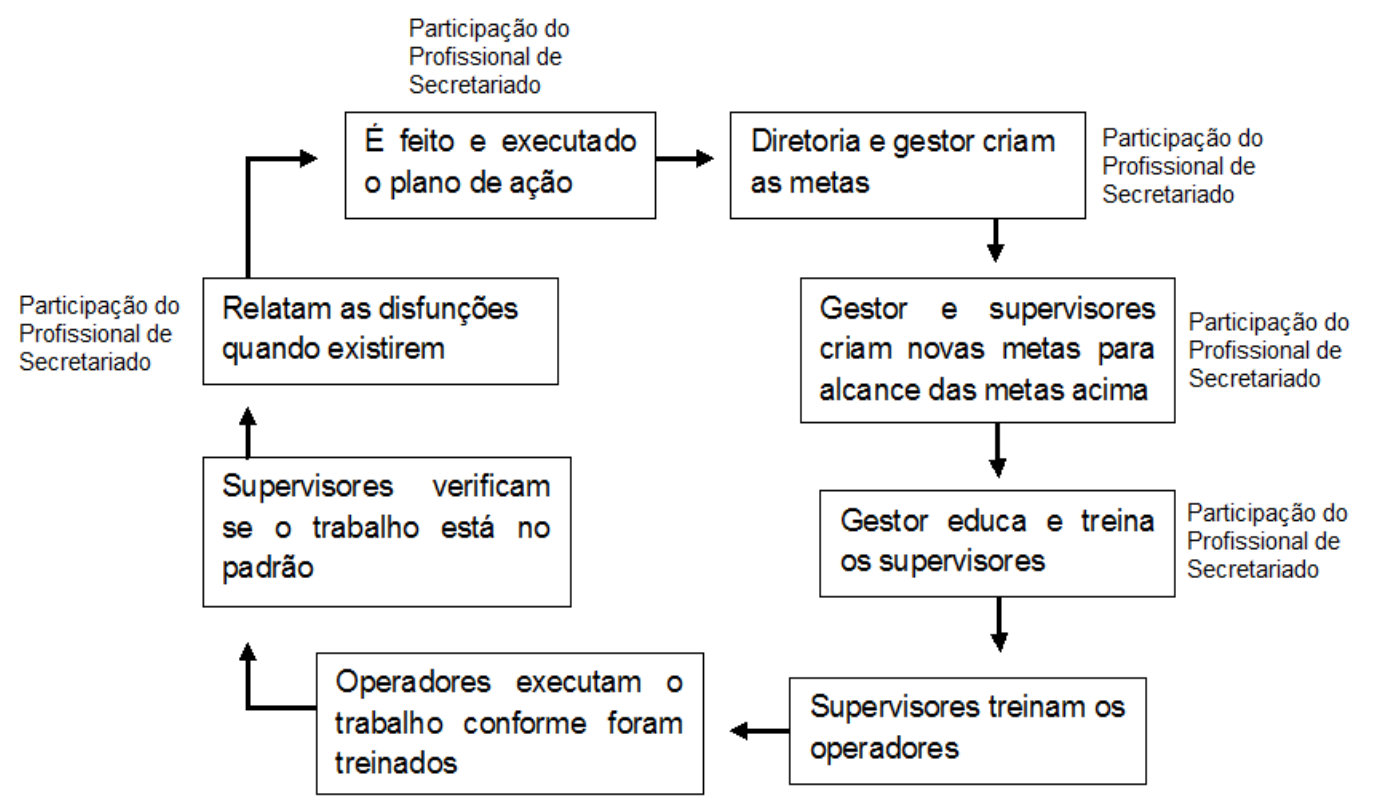

Fonte: Autores da pesquisa.

Observa-se que durante esses processos há a participação do profissional de secretariado nas etapas de criação de metas, educação e treinamento, verificação e relato das disfunções e nos planos de ação. Tal participação é possível diante da possibilidade de atuação desse profissional nos três níveis hierárquicos, uma vez que a base de suas atividades é o assessoramento. Outra justificativa está em suas habilidades e boa percepção, tendo em vista que os problemas no departamento foram identificados por este profissional.

Logo, acredita-se que com essas medidas o departamento terá bons resultados e sairá de sua estagnação, uma vez que com metas definidas e traçadas e com pessoal treinado e supervisionado, sobretudo, com a valorização e desenvolvimento deles a empresa pode fornecer um serviço de qualidade, satisfazer seus clientes e assim permanecer no mercado.

\section{CONSIDERAÇÕES FINAIS}

Este estudo foi realizado a partir da observação empírica do profissional de secretariado que, ao trabalhar na empresa objeto do estudo, verificou que a nota de satisfação variava mensalmente e os motivos de insatisfação eram sempre os mesmos. Após sugerir algumas medidas para o gestor visando à melhoria desta situação, foi possível perceber que durante alguns meses a nota parou de cair permanecendo estável, mesmo que não apresentasse crescimento.

Ao observar os resultados deste estudo, notou-se que a falta de padrão nos processos é mais 
complexa do que era notado no dia a dia. Por meio das entrevistas com os funcionários, cada um deu uma resposta diferente, o que mostra a desorganização do departamento.

Observou-se que o departamento pesquisado não consegue satisfazer majoritariamente uma amostra de 20 clientes (números de 2013) sendo que eles recebem o número de 300 passagens mensais. E que os problemas que geram satisfação são os mesmos durante os três anos de existência da empresa.

No que se refere aos processos, não existem registros, nem padronização deles. Nota-se que o ponto mais crítico do departamento após a falta de objetivos e do entendimento das pessoas em saber qual a missão delas, é que os funcionários não sabem desenvolver bem suas atividades, em virtude da maioria não ter experiência, sobretudo pela ausência de treinamento delas.

E sem o planejamento dos processos, padronização e treinamento, a ausência de padrões justifica os motivos de insatisfação dos clientes, uma vez que todos eles estão relacionados de alguma forma com os processos no departamento. Como se trata de um serviço tangível, ou seja, que é notado, pois é realizado na propriedade do cliente, este percebe e identifica melhor o bom e ruim serviço.

Posteriormente, o ponto responsável pela insatisfação dos clientes são os funcionários e a falta de competência e de treinamento deles. Entretanto, o que evidenciou com as respostas dos colaboradores comparando com a do gestor é que esse não é um problema do pessoal, mas sim, gerencial.

Uma vez que a gerência contrata a maioria das pessoas sem experiência e não as treina, então elas são instruídas por funcionários que não têm conhecimento adequado e/ou passaram pelo mesmo processo delas; não há registros dos processos, então o pessoal aprende de modo verbal e do jeito de cada um. Em seguida, já começam a exercer sua função sem nenhum recurso intelectual e ainda são culpados pelo gestor pelo mau serviço, com a justificativa de que os funcionários não se empenham como deveriam.

Porém, tendo em vista que cada pessoa tem um tipo de entendimento e um modo de aprendizado ao ler um manual ou a realizar um curso online, a empresa, nesse sentido, deve empenhar-se em mostrar, por meio de padrões, as ações e procedimentos esperados.

Por outro lado, além dessa falta de instrução, a gerência também é falha, pois não resolve os problemas naquele momento. Como foi visto na tabela dos motivos de insatisfação, eles são sempre os mesmos. Logo, tendo em vista que o papel da gerência é resolver problemas, a do departamento não tem êxito.

Dessa forma o departamento está estagnado desde o primeiro ano de suas atividades. Não houve crescimento, isto porque as pessoas gastam mais esforços no retrabalho. E isto é um problema para o bom desempenho e crescimento da empresa no mercado, uma vez que a falta de qualidade dos serviços não traz credibilidade para a empresa e os concorrentes ganham competitividade.

Assim, a partir da elaboração das propostas pelo profissional de secretariado executivo é imprescindível a adoção dessas medidas o mais breve possível para que o departamento, e consequentemente a empresa, melhore a qualidade dos seus serviços de modo a satisfazer toda sua 
clientela e assim garanta sua sobrevivência no âmbito, considerando que a empresa estará organizada e preparada desde a contratação dos profissionais até a execução dos serviços.

Destaca-se a importância de futuros estudos em concessionárias automobilísticas, sobretudo na assistência técnica, em virtude da falta de pesquisas nessa área o que limitou o referencial teórico deste estudo.

Espera-se que esta pesquisa contribua não somente para empresas dessa esfera, mas também para qualquer empresa de prestação de serviço, pois a padronização dos processos é primordial para organizações desse âmbito.

\section{REFERÊNCIAS}

Araújo, Luís César (2011). Organização, sistemas e métodos e as tecnologias de gestão organizacional. Vol. 1 (5a ed.) São Paulo: Atlas.

Campos, Vicente Falconi (2004). Gerenciamento da rotina de trabalho do dia a dia. Nova Lima: Editora Falconi.

Caravantes, Geraldo R; Panno, Cláudia C; \& Kloeckner, Mônica C. (2005). Administração: teorias e processos. São Paulo: Pearson Prentice Hall.

Cruz, Tadeu (2011). Sistemas, organizações \& métodos: estudo integrado das novas tecnologias de informação (3a ed.) São Paulo: Atlas.

Dealer (fev.-mar. 2013). Revista bimestral da Federação Nacional da Distribuição de Veículos Automotores (40 ed.), São Paulo.

Gil, Antônio Carlos (2007). Como elaborar projetos de pesquisa (4a ed.- 9a reimpr). São Paulo: Atlas.

. (2010). Como elaborar projetos de pesquisa (5a ed.). São Paulo: Atlas.

Gronroos, Christian (2003). Marketing: gerenciamento e serviços (2a ed.). Rio de Janeiro: Elsevier.

Hoffman, K. Douglas \& Bateson, John E. G. (2003) Marketing de serviços (4a ed.) Reimp. Porto Alegre: Bookman.

. (2009) Princípios de marketing de serviços: conceitos, estratégias e casos (3a ed.) São Paulo: Cengage Learning.

Las Casas, Alexandre Luzzi (2008). Qualidade total em serviços: conceitos, exercícios, casos práticos (6a ed.). São Paulo: Atlas.

Lovelock, Cristopher; Wirtz Jocken \& Hemzo, Miguel Angelo (2011). Marketing de serviços: pessoas, tecnologia e estratégia (7a ed.) São Paulo: Pearson Prentice Hall. 2011.

Muniz, Sérgio Tadeu Gonçalves (2005). Atividades de serviços nas montadoras: Dimensão, estratégias e trajetórias (1998-2004) [tese de doutorado] São Paulo: Universidade de São 
Paulo; 2005. Recuperado em $26 \quad$ julho, $2013 \quad$ de http://www.teses.usp.br/teses/disponiveis/3/3136/tde-03072013-155735/pt-br.php.

Salada, Marcos Osvaldo da Silva (2002). Gerenciamento da rotina através do método de estabilização de processos [dissertação de mestrado] Porto Alegre: Universidade Federal do Rio Grande do Sul, Programa de Pós-Graduação Engenharia de Produção; 2002. Recuperado $\begin{array}{llll}\text { em } & 11 & \text { julho, } & \text { de }\end{array}$ http://www.lume.ufrgs.br/bitstream/handle/10183/2607/000373479.pdf?sequence=1.

Sales, Jefferson David Araujo (2012). Ações coletivas suportadas pela tecnologia da informação em comunidades de prática: os efeitos indutores à configuração dos coletivos inteligentes [tese de doutorado] Recife: Universidade Federal de Pernambuco, Programa de Pós-graduação em Administração.

Thiollent, Michel (2005). Metodologia da pesquisa-ação (14a ed.) São Paulo: Cortez Editora. . (2009). Pesquisa-ação nas organizações (2a ed.). São Paulo: Atlas.

Urdan, André Torres \& Zuñiga, Melby Karina Huertas. (2001). A satisfação com a assistência técnica e lealdade ao fabricante do ramo automobilístico. Recuperado em 12 julho, 2013, de http://www.scielo.br/pdf/rae/v41n3/v41n3a04.pdf. 